role and are based on scant poor quality data, which do not adequately account for case mix.

The study's principal limitation is its confinement to one small, though important, group of patients and services. Our findings may be atypical, and trusts' ratings may reflect outcomes elsewhere in hospital care.

If these findings reflect other areas of hospital care, the government is not yet fulfilling its "commitment to provide patients and the general public with comprehensive, easily understandable information on the performance of their local health services." ${ }^{\prime \prime}$ Outcome ought to be a principal concern alongside process indicators, such as waiting times and cleanliness; to fulfil its aim, the government needs to use specialised clinical databases (accessible through www.docdat.org). ${ }^{5}$

We thank the participating intensive care units and Minesh Tailor at the Intensive Care National Audit and Research Centre.
Contributors: KR and NB devised the study; all authors designed the study and interpreted the data; and NB, KR, and $\mathrm{DH}$ wrote the paper. NB is guarantor.

Funding: None.

Competing interests: None declared.

Ethical approval: Not needed.

1 Department of Health. NHS performance ratings: acute trusts, specialist trusts, ambulance trusts, mental health trusts 2001/02. London: DoH, 2002.

2 Gill K, Black SA, Clarke P, Corbett CRR. Misleading mortality data in league tables. Ann R Coll Surg Engl 2003;85(suppl):S244-7.

Rowan K, Black N. A bottom-up approach to performance indicators through clinician networks. Health Care UK 2000 Spring:42-6.

Rowan KM. Outcome comparisons of intensive care units in Great Britain and Ireland using the APACHE II method [PhD thesis]. Oxford: University of Oxford, 1993.

5 Black N, Payne M. Directory of clinical databases: improving and promoting their use. Qual Saf Health Care 2003;12:348-52.

(Accepted 12 November 2003)

doi 10.1136/bmj.38007.694745.F7

\title{
Pertussis vaccination in infancy and asthma or allergy in later childhood: birth cohort study
}

\author{
Anirban Maitra, Andrea Sherriff, Mansel Griffiths, John Henderson, Avon Longitudinal Study of \\ Parents and Children Study Team
}

Some studies have shown a link between vaccination of infants with whole cell inactivated pertussis vaccine and the later development of asthma and atopy. ${ }^{12} \mathrm{~A}$ randomised controlled trial disagreed with these findings, but follow up was done until only 30 months of age. ${ }^{3}$ Our previous report of the lack of an association between pertussis vaccination and wheezing disorders was based on outcomes in early childhood. ${ }^{4}$ In this study we have examined the association between pertussis vaccination in infancy and asthma or atopy by age 7.5 years in a large, population based birth cohort.

\section{Participants, methods, and results}

Participants were the 13971 children who survived to 1 year in the Avon longitudinal study of parents and children. The study method has been described previously, ${ }^{5}$ and details can be found on the study website (www.alspac.bris.ac.uk). We obtained the vaccination status for each child from the child health surveillance database. We categorised children with regard to pertussis as fully vaccinated (completed a primary course of diphtheria, tetanus, and pertussis vaccination), partially vaccinated (completed a primary course of diphtheria and tetanus but did not receive pertussis vaccine) or non-vaccinated (no vaccinations). We excluded other combinations from analysis. We obtained three wheezing outcomes based on parental self report questionnaires (asthma at 69-81 months, wheeze with whistling on the chest at 69-81 months, and asthma diagnosed by a doctor at 91 months) and one atopy outcome based on skin prick tests at age 7 years. We defined atopy as one or more positive reactions (wheal $\geq 2 \mathrm{~mm}$ ) to a panel of three common allergens. We selected several variables as potential confounders of the relation between exposure and outcome, which were, however, not considered to be in the causal pathway. These were, from mother's questionnaire data: maternal education, maternal smoking during pregnancy, maternal history of asthma or eczema, maternal financial difficulties, damp housing, overcrowding, child's ethnicity, number of siblings, contact with cats in the home, duration of breast feeding, and passive exposure to tobacco smoke; and, from medical records: birth weight, sex, gestational age, and maternal age at delivery. We used Pearson's $\chi^{2}$ (or Fisher's exact test if the predicted number of subjects in any category was less than five) for our data analysis of univariable associations between vaccination status and possible confounders and principal outcomes. We used multivariable logistic regression models to evaluate associations between immunisation status and asthma and allergy outcomes while controlling for potential confounders.

Vaccination history was available for 13810 children, of whom 13109 (94.9\%) were fully vaccinated, 446 did not have pertussis vaccination (340 non-vaccinated; 106 partially vaccinated), and 255 had some other combination. The table shows numbers of subjects with outcome data for each of the principal outcomes. The cumulative prevalence of asthma diagnosed by doctors was $20.3 \%(n=1597)$ at 91 months. The prevalence of reported asthma at $69-81$ months was $12.4 \%(n=1024)$, reported wheeze with whistling at 69-81 months 9.8\% $(\mathrm{n}=798)$ and atopy at 7 years $20.5 \%(\mathrm{n}=1324)$. The table shows the adjusted and unadjusted odds ratios and $95 \%$ confidence intervals from logistic regressions for each of the principal outcomes. Although unadjusted analyses showed significant associations (asthma at

$$
\text { A supplemental table is on bmj.com }
$$

This article was posted on bmi.com on 19 March 2004: http://bmj.com/ cgi/doi/10.1136/bmj.38045.858889.EB
Bristol Royal Hospital for Children,

Department of Respiratory Medicine, Bristol BS2 8BJ

Anirban Maitra paediatric respiratory medicine

John Henderson senior lecturer in child health

Avon Longitudinal Study of Parents and Children, University of Bristol,

Department of

Community-based

Medicine, Bristol

BS8 1TQ

Andrea Sherriff

statistician

St Michael's

Hospital, Ear, Nose, and Throat

Department, Bristol BS2 8EG

Mansel Griffiths consultant ear, nose, and throat surgeon

Correspondence to:

A Maitra

dramaitra@

yahoo.co.uk

BMJ 2004;328:925-6 
Odds ratios with $95 \%$ confidence intervals for outcome variables according to pertussis vaccination status

\begin{tabular}{|c|c|c|c|c|}
\hline Outcome variable & Non-vaccinated ${ }^{*}$ & Partially vaccinated $\dagger$ & Fully vaccinated & $P$ value \\
\hline \multicolumn{5}{|c|}{ Asthma at age 69-81 months (1024/8240) } \\
\hline $\begin{array}{l}\text { Prevalence in \% } \\
\text { (No/total) }\end{array}$ & $8.2(12 / 146)$ & $20.3(14 / 69)$ & $12.4(998 / 8025)$ & \\
\hline Unadjusted & 1.00 & 2.84 (1.24 to 6.53$)$ & $2.05(0.8$ to 5.23$)$ & 0.05 \\
\hline Adjusted & 1.00 & 1.59 (0.88 to 2.97$)$ & $1.06(0.58$ to 1.95$)$ & $>0.1$ \\
\hline \multicolumn{5}{|c|}{ Periods of wheeze at age $69-81$ months $(798 / 8114)$} \\
\hline $\begin{array}{l}\text { Prevalence in \% } \\
\text { (No/total) }\end{array}$ & $9.0(13 / 144)$ & $16.2(11 / 68)$ & $9.8(774 / 7902)$ & \\
\hline Unadjusted & 1.00 & $1.95(0.82$ to 4.6$)$ & 1.09 (0.62 to 1.94$)$ & 0.2 \\
\hline Adjusted & 1.00 & 1.55 (0.55 to 4.37$)$ & 0.94 (0.50 to 1.78$)$ & 0.2 \\
\hline \multicolumn{5}{|c|}{ Doctor diagnosed asthma at age 91 months (1597/7850) } \\
\hline $\begin{array}{l}\text { Prevalence in \% } \\
\text { (No/total) }\end{array}$ & $15.8(23 / 146)$ & $36.2(21 / 58)$ & $20.3(1553 / 7667)$ & \\
\hline Unadjusted & 1.00 & $3.03(1.51$ to 6.09$)$ & 1.36 (0.87 to 2.13$)$ & 0.005 \\
\hline Adjusted & 1.00 & 1.93 (0.86 to 4.33$)$ & 0.98 (0.61 to 1.58$)$ & 0.1 \\
\hline \multicolumn{5}{|c|}{ Atopy at age 7 years $(1324 / 6463)$} \\
\hline Prevalence in \% (No) & $17.7(22 / 124)$ & $15.4(6 / 39)$ & $20.6(1296 / 6300)$ & \\
\hline Unadjusted & 1.00 & 0.84 (0.32 to 2.26$)$ & $1.20(0.75$ to 1.91$)$ & 0.6 \\
\hline Adjusted & 1.00 & 1.05 (0.35 to 3.21$)$ & 1.18 (0.69 to 2.03$)$ & 0.8 \\
\hline
\end{tabular}

${ }^{*}$ No primary vaccinations, including pertussis

$\dagger$ Diphtheria and tetanus $\geq 3$ doses and no pertussis.

$\ddagger$ Triple (diphtheria, tetanus, and pertussis) vaccine $\geq 3$ doses.

69-81 months, $\mathrm{P}=0.05$; doctor diagnosed asthma, 91 months, $\mathrm{P}=0.005$ ), it should be noted that, because of small numbers in some groups, the confidence intervals were wide and the results did not support the hypothesis. When we adjusted for potential confounding factors we detected no significant associations $(\mathrm{P}=0.1-0.8)$

\section{Comment}

These findings confirm and extend our previous observations of the lack of an independent association between pertussis vaccination in infancy with inactivated, whole cell vaccine and the subsequent development of asthma or atopy during later childhood.

Acknowledgments: We thank the mothers and children who took part and the midwives for their cooperation and help in recruitment. The whole ALSPAC study team comprises interviewers, computer technicians, laboratory technicians, clerical workers, research scientists, volunteers, and managers who continue to make the study possible. The ALSPAC study is part of the European Longitudinal Study of Parents and Children initiated by the World Health Organization.

Contributors: MG had the original idea. AM, AS, JH did the analysis. All authors contributed to the interpretation of the data. AM wrote the paper. $\mathrm{JH}$ will act as guarantor.

Funding: Core funding for the long term follow up of the cohort came from the Medical Research Council, the Wellcome Trust, the UK Department of Health, the Department of the Environment, DfEE, the National Institutes of Health, and a variety of medical research charities. No specific funding was obtained for this analysis.
Competing interests: None declared.

Ethical approval: Avon Longitudinal Study of Parents and Children Ethics and Law Committee.

1 Odent MR, Kimmel T. Pertussis vaccination and asthma: is there a link? JAMA 1994;272:592-593.

Kemp T, Pearce N, Fitzharris P, Crane J, Fergusson D, St George I Wickens K, Beasley R. Is infant immunization a risk factor for childhood asthma or allergy? Epidemiology 1997;8:678-680.

3 Nilsson L, Kjellman N-IM, Björksten B. A randomised controlled trial of the effect of pertussis vaccines on atopic disease. Arch Pediatr Adolescent Med 1998;152:734-738.

4 Henderson AJ, North K, Griffiths M, Harvey I, Golding J, ALSPAC Study Team. Pertussis vaccination and wheezing illnesses in young children: prospective cohort study. BMJ 1999;318:1173-1176.

5 Golding J, Pembrey M, Jones R., ALSPAC Study Team. ALSPAC-the Avon longitudinal study of parents and children I. Study methodology. Paediatr Perinatal Epidemiol 2001:15:74-87.

(Accepted 8 December 2003)

doi $10.1136 /$ bmj.38045.858889.EB

\section{Corrections and clarifications}

British Hypertension Society guidelines for hypertension management 2004 (BHS-IV): summary

An error occurred in the order of the reference list in this Education and Debate article by Bryan Williams et al (13 March, pp 634-40). Reference 8 in the published version (Williams et al) should have been reference 3 ; and the references published as 3 (Ramsay et al) to 7 (O'Brien et al) in the reference list should then have been renumbered and become references 4 to 8 . The two references cited in the footnote to table 1 should be renumbered as 6 (European Society of Hypertension-European Society of Cardiology) and 7 (WHO-International Society of Hypertension); but the other references cited in the text of the article are correct. The pdf (but not the HTML) version on bmj.com has been amended.

Recent developments in secondary prevention and cardiac rehabilitation after acute myocardial infarction As a result of technology problems, some amendments from the authors did not make it into this clinical review by Hasnain Dalal and colleagues (20 March, pp 693-7). In box 2, we should have added the website address for SEARCH (the study of additional reductions in cholesterol and homocysteine): www.ctsu.ox.ac.uk/projects/ search.shtml. And the penultimate sentence of the subsection "Angiotensin converting enzyme inhibitors" should have said that rates of revascularisation (not rates of readmission for heart failure) were reduced in patients who took ramipril.

Obituary:Leonard ("Johnnie") Walker

Our weekly quest to squeeze in as many obituaries as possible led to the last minute deletion of an important sentence from this obituary $(B M J$ 2003;327:1291). We omitted to say "Christianity was an abiding passion and his faith directed his life." We have apologised to Dr Walker's wife.

\section{Is Dad mad, doctor?}

I had just put away the pleural aspiration kit and labelled the samples, and had returned to the patient, whose family had now arrived, to check that he was comfortable.

One of the adult children greeted me with the question, "Do you think Dad's mad, doctor?"

"Mad?" I was a little bemused as to where this had come from.
"Yes. He said you are going to send off the fluid from his lungs for psychology."

After a few puzzled moments, the penny dropped: "No, not psychology, cytology."

James S Dawson senior house officer, Queen's Medical Centre, Nottingham 